\title{
Relation of Animal Size to Convergence, Divergence, and Neuronal Number in Peripheral Sympathetic Pathways
}

\author{
Dale Purves, Eric Rubin, William D. Snider, ${ }^{1}$ and Jeff Lichtman \\ Department of Anatomy and Neurobiology, Washington University School of Medicine, St. Louis, Missouri 63110
}

The enormous range of animal size raises a fundamental problem: How do larger animals maintain adequate control of peripheral structures that are many times more massive and extensive than the homologous structures in smaller animals? To explore this question, we have determined neuronal number, the number of axons that innervate each neuron (convergence) and the number of neurons innervated by each axon (divergence), in a peripheral sympathetic pathway of several mammals (mouse, hamster, rat, guinea pig, and rabbit). The average adult weights of these species vary over approximately a 65 -fold range. However, the number of superior cervical ganglion cells increases by only a factor of 4 between the smallest of these animals (mice; about $25 \mathrm{gm}$ ) and the largest (rabbits; about $1700 \mathrm{gm}$ ); the number of spinal preganglionic neurons that innervate the ganglion increases by only a factor of 2 . Thus, the number of nerve cells in the sympathetic system does not increase in proportion to animal size. On the other hand, our results indicate that there are systematic differences across these species in the number of axons that innervate each ganglion cell and in the number of ganglion cells innervated by each axon. We suggest that modulation of convergence and divergence in sympathetic ganglia allows this part of the nervous system to effectively activate homologous peripheral targets over a wide range of animal size.

The largest mammalian species are at least 10 million times the size of the smallest (Calder, 1984; Schmidt-Nielsen, 1984). Homologous neural pathways in animals of different size must therefore initiate vastly different amounts of work. One solution to this problem is apparently the production and maintenance of more nerve cells in larger animals (Bok, 1959; Cobb, 1965; Holloway, 1968; Thompson, 1917). However, the weight of brain, at least, increases at a lesser rate across species than the weight of the body as whole (Cobb, 1965). Whether this disproportion means that neuronal number does not keep pace with animal size is unclear; neither is it known how such a disproportion might be compensated for in larger animals.

In order to explore these issues we have examined several quantitative relations between pre- and postsynaptic neurons in the peripheral sympathetic systems of five mammals (mouse, hamster, rat, guinea pig, and rabbit). We have chosen the superior cervical ganglion and its preganglionic supply in the spinal cord as a relatively simple neural pathway, in which the number

\footnotetext{
Received Apr. 8, 1985; revised May 20, 1985; accepted May 28, 1985

We are grateful to Pat Newton for skillful assistance and to C. Forehand, $\mathbf{R}$. Hadley, J. Sanes, and J. Voyvodic for useful comments. This work was supported by NIH Grants 18629 and 11699 ; W.D.S. was supported by a Morison Fellowship from the Grass Foundation.

1 Present address: Department of Neurology, Washington University School of Medicine, 660 South Euclid Avenue, St. Louis, MO 63110. Correspondence should be sent to Dale Purves, M.D., Department of Anatomy and Neurobiology, at this address.

Copyright (C) 1986 Society for Neuroscience $0270-6474 / 86 / 010158-06 \$ 02.00 / 0$
}

of pre- and postsynaptic neurons, the number of axons innervating each ganglion cell, and the number of ganglion cells innervated by each axon can be assessed with reasonable accuracy. Our results suggest that increasing degrees of convergence and divergence compensate for the progressive discrepancy between neuronal number and target size in the autonomic systems of progressively larger animals.

\section{Materials and Methods}

\section{Number of neurons in the superior cervical ganglia of different species}

Young adult mice (about $25 \mathrm{gm}$ ), hamsters (about $110 \mathrm{gm}$ ), rats (about $175 \mathrm{gm}$ ), guinea pigs (about $380 \mathrm{gm}$ ), and rabbits (about $1700 \mathrm{gm}$ ) were used in all experiments; females were chosen because of a significant sex difference in the number of neurons in the rat superior cervical ganglion (Wright and Smolen, 1983). The number of cells in the superior cervical ganglia of these five species was determined by conventional techniques (see, for example, Gorin and Johnson, 1980). Animals were sacrificed and perfused through the heart with saline. The right superior cervical ganglion was removed and fixed by immersion overnight in $10 \%$ formalin-saline. Ganglia were dehydrated in graded ethanol solutions, cleared in methylsalicylate, and embedded in paraffin. Serial sections of 5 or $7 \mu \mathrm{m}$ were cut in the horizontal plane and stained with thionin.

Because the number of nucleoli is highly variable among these different species, the unit chosen for counting was the cell nucleus; $7 \mu \mathrm{m}$ was the greatest section thickness in which nuclei could be counted without ambiguity in all five species. A periodic sample of sections representing $5-20 \%$ of the volume of the ganglion was counted. Overcounting due to inclusion of single nuclei in multiple sections was corrected by the method of Abercrombie (1946); nuclear diameters were measured in transverse sections of the contralateral ganglia. The average nuclear diameter in these species ranged from 8 to $13 \mu \mathrm{m}$; the value for each species was used in making corrections of the raw counts (Table 1).

Rabbits and guinea pigs have significant numbers of ganglion cells with two nuclei (see Table 2 in Forehand, in press, and Fig. 3, below). In 15-20 $\mu \mathrm{m}$ sections, the majority of neurons in both these species appeared to be binucleate. Examination of the surface of the guinea pig superior cervical ganglion with Nomarski optics confirmed that most, if not all, of the cells had two nuclei. For purposes of counting, we have assumed that all superior cervical neurons in both rabbit and guinea pig are binucleate. If some cells in fact contained only one nucleus, we may have slightly underestimated the total counts in these two species.

\section{Number of neurons in the preganglionic population of different species}

Animals of these five species were anesthetized with pentobarbital and the cervical sympathetic trunk exposed on the right side. The trunk was cut and the central end was dipped immediately into a small styrofoam dish filled with a solution of $50 \%$ HRP and $1 \%$ lysolecithin (Frank et al., 1981). The immersed cut nerve was kept under direct observation for $40 \mathrm{~min}$; the dish was then covered with Parafilm and the wound closed. After $48 \mathrm{hr}$, the animals were reanesthetized and fixed by perfusion through the heart; the spinal cords were then removed from lower cervical to lower thoracic levels and sectioned on a Vibratome at 60 
Table 1. Number of superior cervical ganglion cells in five species of small mammals

\begin{tabular}{lrrrrl} 
& \multicolumn{2}{l}{$\begin{array}{l}\text { Weight } \\
\text { Animal }\end{array}$} & $\begin{array}{l}\text { Raw } \\
\text { (gm) }\end{array}$ & \multicolumn{1}{l}{ count } & \multicolumn{2}{l}{$\begin{array}{l}\text { Coction } \\
\text { rected }\end{array}$} & Corrected \\
Mouse & 32 & 21,310 & 0.43 & 9163 & $10,389 \pm 585$ \\
& 27 & 30,440 & 0.35 & 10,654 & \\
& 20 & 27,642 & 0.43 & 11,886 & \\
& 20 & 22,911 & 0.43 & 9852 & \\
Hamster & 90 & 40,824 & 0.42 & 17,146 & $16,697 \pm 1178$ \\
& 100 & 31,927 & 0.44 & 14,048 & \\
& 120 & 44,706 & 0.44 & 19,671 & \\
Rat & 90 & 37,912 & 0.42 & 15,923 & \\
& 170 & 50,871 & 0.43 & 21,877 & $26,369 \pm 1621$ \\
& 150 & 72,614 & 0.36 & 26,141 & \\
& 160 & 70,720 & 0.41 & 28,995 & \\
Guinea pig & 170 & 64,690 & 0.44 & 28,464 & \\
& 360 & 76,730 & 0.45 & 34,529 & $35,546 \pm 2243$ \\
& 480 & 106,958 & 0.36 & 38,505 & \\
& 370 & 106,785 & 0.37 & 37,510 & \\
Rabbit & 400 & 75,998 & 0.39 & 29,639 & \\
& 1600 & 95,446 & 0.41 & 39,133 & $40,517 \pm 2638$ \\
& 1600 & 101,214 & 0.39 & 39,473 & \\
& 1650 & 88,755 & 0.40 & 35,502 & \\
& 1700 & 114,186 & 0.42 & 47,958 &
\end{tabular}

Four animals of each species were examined. Correction factors here and in Table 2 were calculated by the Abercrombie formula (section thickness/average nuclear diameter + section thickness).

$\mu \mathrm{m}$ in the horizontal plane (see Rubin and Purves, 1980, for details). After histochemical processing, the number of HRP-labeled preganglionic neurons was counted at $125 \times$. Only labeled cell profiles containing nuclei were counted. The spinal cords of a scparate scrics of animals were sectioned in the transverse plane to determine the dorsalventral dimension of the nuclei of the labeled cells in each species. This measurement was then used to correct the raw counts from the horizontal sections (see above).

Although we have no independent measure of labeling efficiency, an estimate of the adequacy of the procedure was made by examining the segmental distribution of labeled preganglionic neurons in the spinal cord. For each species, this distribution closely matched the results of parallel physiological determinations (see Rubin and Purves, 1980, and below). Even preganglionic cells labeled in the segments farthest from the site of HRP application were well marked. However, whether all the preganglionic neurons are labeled by HRP is uncertain; the significance of this problem for our results is discussed below.

\section{Results}

\section{The number of neurons in superior cervical ganglia of different mammals}

Counts of neurons in the supcrior cervical ganglia of five species of small mammals are presented in Table 1. Comparison of the smallest and the largest of these animals shows that body weight increases more than 60 -fold. In contrast, the number of superior cervical ganglion cells increases only about $4 \times$.

The counts given here are in general agreement with some values that have appeared in the literature (e.g., for the rat see Dibner and Black, 1978; Gorin and Johnson, 1980; Wright et al., 1983). On the other hand, our counts differ by as much as a factor of 2 from other published values (e.g., for the rat, see Brooks-Fournier and Coggeshall, 1981; Hendry and Campbell, 1976; for the guinea pig and rabbit, see Johnson et al., 1980, 1982). In general, determinations of ganglion cell numbers depend on the ability to identify unambiguously the structure
Table 2. Number of labeled preganglionic neurons following application of HRP to the cervical sympathetic trunk

\begin{tabular}{|c|c|c|c|c|c|}
\hline Animal & $\begin{array}{l}\text { Weight } \\
\text { (gm) }\end{array}$ & $\begin{array}{l}\text { Raw } \\
\text { count }\end{array}$ & $\begin{array}{l}\text { Cor- } \\
\text { rection } \\
\text { factor }\end{array}$ & $\begin{array}{l}\text { Cor- } \\
\text { rected } \\
\text { count }\end{array}$ & $\begin{array}{l}\text { Corrected } \\
\text { mean } \pm \text { SEM }\end{array}$ \\
\hline \multirow[t]{4}{*}{ Mouse } & 28 & 927 & \multirow[t]{4}{*}{0.87} & 806 & \multirow[t]{4}{*}{$728 \pm 140$} \\
\hline & 25 & 1189 & & 1034 & \\
\hline & 28 & 658 & & 572 & \\
\hline & 26 & 575 & & 500 & \\
\hline \multirow[t]{4}{*}{ Hamster } & 135 & 862 & \multirow[t]{4}{*}{0.87} & 750 & \multirow[t]{4}{*}{$665 \pm 77$} \\
\hline & 120 & 749 & & 652 & \\
\hline & 130 & 553 & & 481 & \\
\hline & 110 & 892 & & 776 & \\
\hline \multirow[t]{4}{*}{ Rat } & 200 & 1404 & \multirow[t]{4}{*}{0.84} & 1179 & \multirow[t]{4}{*}{$969 \pm 127$} \\
\hline & 205 & 1244 & & 1045 & \\
\hline & 160 & 786 & & 660 & \\
\hline & 165 & 1179 & & 990 & \\
\hline \multirow[t]{5}{*}{ Guinea pig } & 345 & 2247 & \multirow[t]{5}{*}{0.84} & 1887 & \multirow[t]{5}{*}{$1324 \pm 182$} \\
\hline & 370 & 1576 & & 1324 & \\
\hline & 405 & 1347 & & 1131 & \\
\hline & 360 & 1083 & & 910 & \\
\hline & 370 & 1631 & & 1370 & \\
\hline \multirow[t]{4}{*}{ Rabbit } & 1500 & 1625 & \multirow[t]{4}{*}{0.81} & 1316 & \multirow[t]{4}{*}{$1489 \pm 243$} \\
\hline & 1800 & 2614 & & 2117 & \\
\hline & 1600 & 1502 & & 1217 & \\
\hline & 2000 & 1610 & & 1304 & \\
\hline
\end{tabular}

counted (nucleolus, nucleus, or cell profile), and the accuracy of the correction factors applied. Our purpose here is to compare species; for this reason, a uniform method of counting and correction was applied to all ganglia. Even if our absolute values are to some degree imprecise, the relative differences between animals are likely to be quite accurate.

\section{The number of preganglionic neuroms projecting to the superior cervical ganglion in different mammals}

The number of preganglionic neurons retrogradely labeled by HRP application to the cervical trunk also increases in larger species (Table 2). These values are in general agreement with most previous determinations in those species that have been examined in this way (for the rat, see Murata et al., 1982; Rando et al., 1981; for the guinea pig, see Dalsgäard and Elfvin, 1979; Purves and Wigston, 1983).

The number of preganglionic neurons determined by retrograde labeling is considerably lower than the values estimated from axon counts of the cervical sympathetic trunk (Aguayo et al., 1973; Brooks-Fournier and Coggeshall, 1981; Murata et al., 1982; Purves, 1976). This raises the possibility that each preganglionic neuron has more than one axonal branch in the cervical trunk. Alternatively, this method of HRP application may systematically underestimate the number of preganglionic neurons (see, for example, Wesselmann and McLachlan, 1984). In spite of uncertainties regarding the efficacy of this technique, our comparisons of preganglionic cell numbers across species, like the comparisons of ganglion cell numbers, are likely to be valid.

As in the case of superior cervical ganglion cells, the rate of increase in preganglionic cell number is much smaller than the rate of change in the body size of the various animals examined: the largest (rabbit) has only twice as many preganglionic neurons as the smallest (mouse). As a consequence of the changes in 


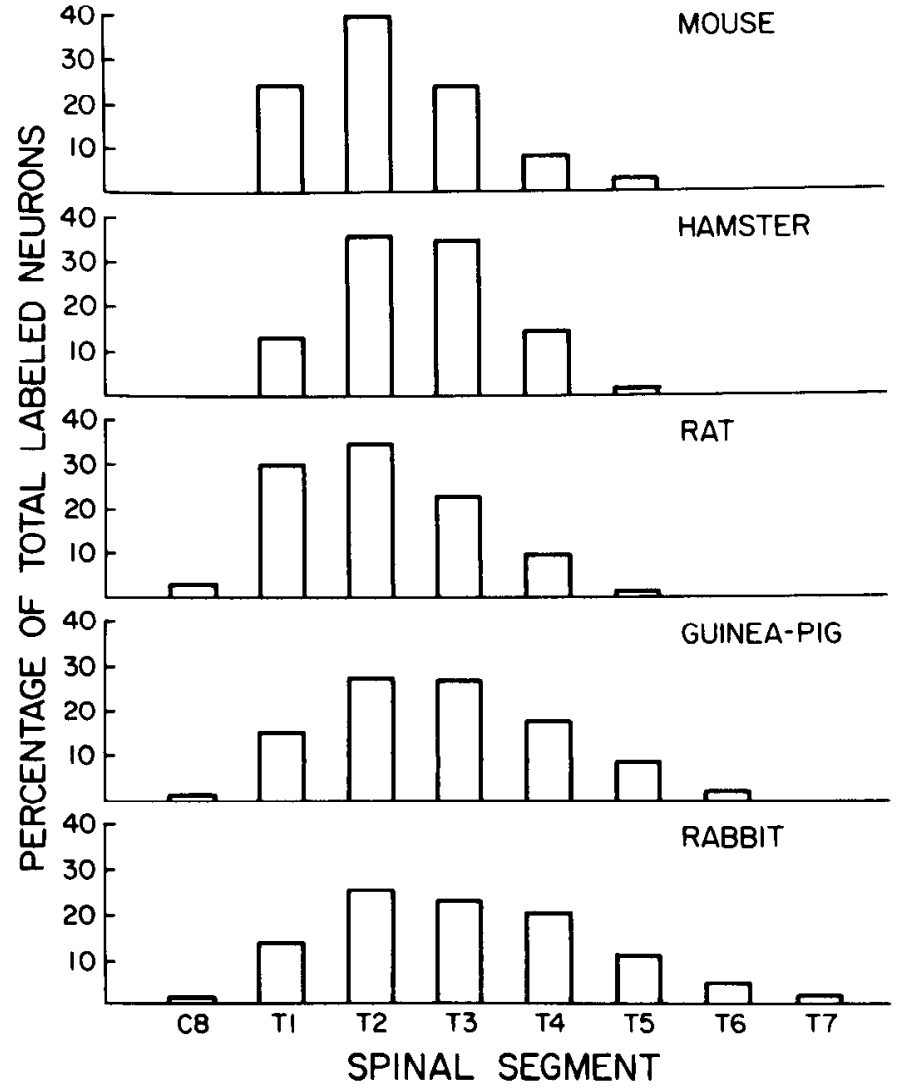

Figure 1. Segmental distribution in the spinal cord of retrogradely labeled preganglionic cell bodies following application of HRP to the cervical sympathetic trunk. For each species, the distribution is the average of the results in four animals (except for the guinea pig, where $n=5$ ). In progressively larger animals, the cells projecting to the superior cervical ganglion arise from a larger number of segments, spreading principally in the caudal direction. The numbers of neurons in each species are given in Table 2.

ganglion cell and preganglionic neuron number, the ratio of ganglion cells to preganglionic cells increases by a factor of 2 among these species (cf. Tables 1, 2 and Fig. 2).

\section{The distribution of preganglionic neurons in different mammals}

The segmental distribution of the preganglionic neurons innervating the superior cervical ganglion also varies in these species (Fig. 1). In general, the preganglionic neurons supplying the ganglion occupy more segments in progressively larger animals.

Table 3. Estimated number of ganglion cells innervated by each preganglionic neuron (neural unit size) in various species

Mean no. of preganglionic neurons innervating Neural each ganglion cell unit size

\begin{tabular}{lrr}
\hline Mouse & 4.5 & 64 \\
Hamster & 7.2 & 180 \\
Rat & 8.7 & 237 \\
Guinea pig & 12.3 & 330 \\
Rabbit & 15.5 & 422
\end{tabular}

The values of neural unit size are based on the information in Tables 1 and 2 , and the average degree of preganglionic convergence onto ganglion cells (Purves and Lichtman, 1985). The calculation is given in the text.

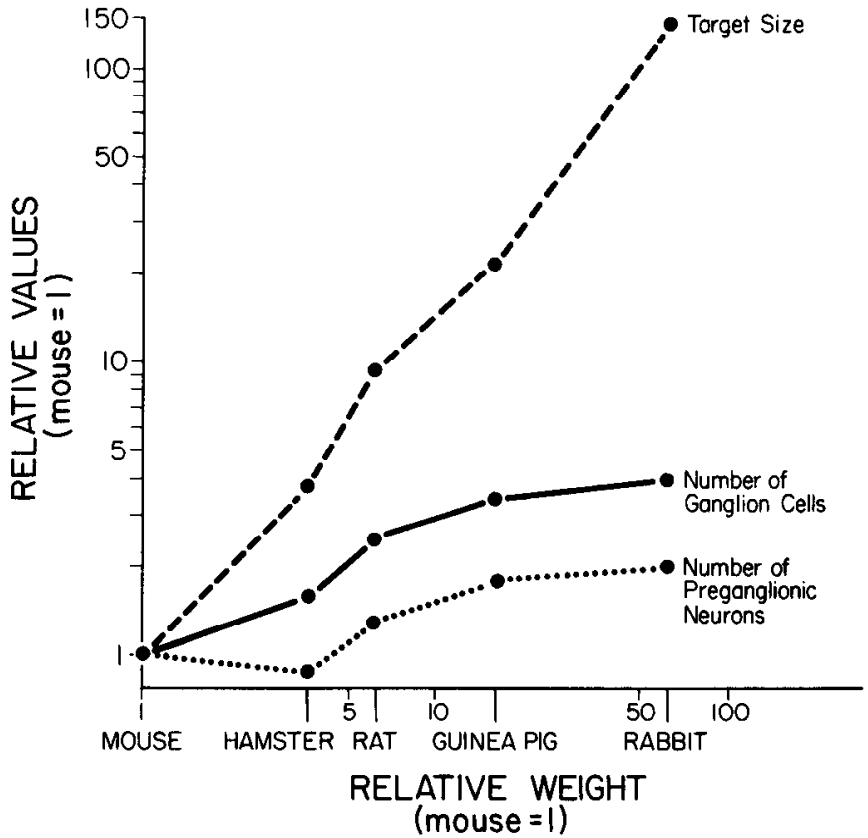

Figure 2. Summary of the relations between target size, the number of ganglion cells, and the number of preganglionic neurons in the five species examined. The values for these parameters, relative to the mouse, are plotted against animal size (weight in gm; log-log scale). The eyeball was taken as a representative target of the superior cervical ganglion (wet weight; $n=4$ for each species). Note that the increase in target size is approximately the same as the increase in body weight among these animals.

Thus, in the mouse, the cells innervating the superior cervical ganglion are distributed across five segments (T1-T5), whereas in the rabbit, the cells are distributed across eight segments (C8T7). The systematic change in the segmental distribution of cells supplying the ganglion closely matches physiological studies of ganglionic innervation in these same species (Purves and Lichtman, 1985; Purves and Lichtman, unpublished observations). A consistent shift was also seen in the distribution of labeled cells within the transverse plane of the spinal cord. In all the animals examined, labeled cells in rostral segments lay predominantly within the lateral funiculus and the intermediolateral nucleus, whereas in progressively more caudal segments, the labeled cells were located more medially (in the intercalated nucleus and dorsal to the central canal; see Rubin and Purves, 1980).

\section{Increasing neural unit size in larger animals}

Intracellular recording shows that the number of preganglionic axons innervating superior cervical ganglion cells in these species varies systematically according to animal size. Ganglion cells in the mouse are, on average, innervated by about four to five different preganglionic axons, whereas the homologous neurons in the rabbit are innervated by about 15-16 different preganglionic axons (Purves and Lichtman, 1985). The convergence onto ganglion cells in the intermediate sized species (rats, hamsters, and guinea pigs) varies proportionately.

With this information, the number of ganglion cells contacted by a single preganglionic neuron (the neural unit size) was estimated using the following formula:

$$
\text { Neural unit size }=\frac{\text { No. of postsynaptic cells }}{\text { No. of presynaptic cells }} \times \text { convergence }
$$

The larger animals in our series have progressively larger neural 

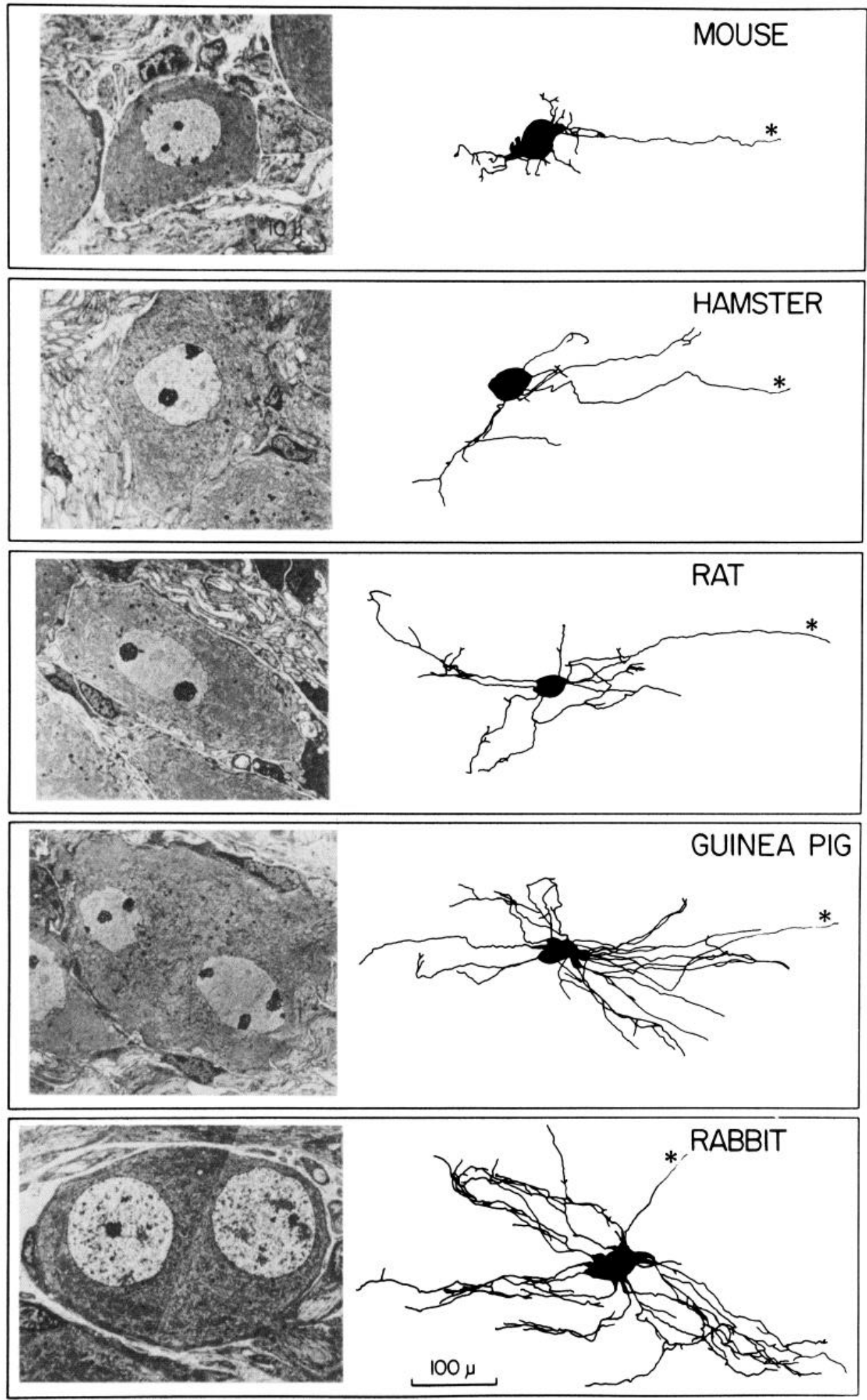

Figure 3. Structural differences of superior cervical ganglion cells associated with differences in animal size. Left, Low-power EMs of ganglion cells in different species showing typical changes in cell size and nuclear number (kindly provided by C. J. Forehand). The average diameter of ganglion cells increases from $18.6 \mu \mathrm{m}$ in the mouse to $30.2 \mu \mathrm{m}$ in the rabbit $(n=100)$. Right, Camera lucida drawings of HRP-filled ganglion cells showing typical changes in dendritic geometry according to animal size (from Purves and Lichtman, 1985). units (Table 3). Thus, each preganglionic neuron in the mouse innervates 64 ganglion cells, on average, whereas in the rabbit, each preganglionic neuron contacts an average of 422 ganglion cells. The values of neural unit size for the other animals studied were intermediate and progressed in the same order as increasing body weight.

\section{Discussion}

\section{Numbers of neurons and animal size}

If the numbers of neurons in the sympathetic nervous system of various species increased in proportion to body size, one would expect the rabbit superior cervical ganglion to comprise 
more than $65 \times$ as many neurons as the superior cervical ganglion in the mouse. In fact, the superior cervical ganglion of a rabbit contains only about $4 \times$ as many neurons as the ganglion of the mouse; moreover, the number of homologous preganglionic cells is larger by only a factor of 2 . These relationships are summarized in Figure 2. Clearly, a larger number of neurons is not the sole solution to the problem of achieving neural control over the progressively greater mass of sympathetic end organs in larger animals.

\section{Changes in neuronal structure and animal size}

There are several systematic differences in the structure of sympathetic ganglion cells across these species (Fig. 3). For instance, the average diameter of superior cervical ganglion cells increases according to animal size; moreover, superior cervical ganglion cells have multiple nuclei in larger species. Most strikingly, ganglion cells in larger animals bear progressively more complex dendritic arbors (Fig. 3; Purves and Lichtman, 1985). Variation in the complexity of dendritic arbors has also been noted in other comparative studies. For example, the total dendritic length of nominally homologous pyramidal cells in the cerebral cortex of mouse, rat, guinea pig, and rabbit increases progressively according to animal size (Bok, 1959; see also Nieuwenhuys, 1967). Finally, it seems likely that the terminal arborizations of ganglion cell axons are more extensive in larger animals. Although we do not know to what extent peripheral sympathetic targets in larger animals comprise more cells, larger cells, or more end organs (e.g., hair follicles or blood vessels), each ganglion cell in larger species must ramify more extensively in the periphery. This conclusion follows simply from the small increase in ganglion cell number compared to the large increase in target size across these species (Fig. 2).

The structure of preganglionic neurons also changes systematically in these animals. For example, the average diameter of preganglionic neurons increases from $9.0 \mu \mathrm{m}$ in the mouse to $13.6 \mu \mathrm{m}$ in the rabbit $(n=150)$. The finding that each preganglionic neuron in larger animals innervates a greater number of ganglion cells (Table 3 ) implies that the terminal arbor of preganglionic axons, as the terminal branching of postganglionic axons, increases in relation to animal size. Finally, the number of synapses made on each ganglion cell increases substantially across these species (Forehand, in press); therefore each preganglionic neuron must elaborate more synaptic boutons in the larger of these animals. Whether preganglionic neurons in larger animals bear more complex dendrites (as do ganglion cells) is not yet known.

\section{Compensatory mechanisms in larger animals}

These several differences may, of course, reflect adaptations to a number of different functional requirements in these species. Nevertheless, it is obviously of interest to ask how these differences in dendritic complexity and axonal branching might be used to meet the particular requirements arising from variation of size.

One way that limited numbers of preganglionic neurons appcar to cnhance their peripheral effect in larger animals is to individually innervate more ganglion cells. Although it is difficult to estimate with much precision the number of ganglion cells innervated by each preganglionic axon, the average neural unit size of each preganglionic neuron in the mouse is about 60 , whereas in the rabbit this value is on the order of 400 . In general, larger neural units amplify the peripheral effect of each action potential in a preganglionic neuron. As a consequence, the mass of tissue that is ultimately activated by each preganglionic neuron in a large animal like the rabbit is considerably greater than the mass driven by a preganglionic neuron in a small mammal like the mouse (see Fig. 2). Such modulation of neural unit size may allow each preganglionic neuron in larger animals to have the same relative motor influence as individual preganglionic neurons in smaller animals.

Two factors appear to contribute to the larger neural unit size in the superior cervical ganglia of larger species. The first is a modest increase in the ratio of ganglion cells to preganglionic neurons in larger animals (see Fig. 2). A second factor is the greater degree of convergence of preganglionic neurons onto sympathetic ganglion cells in larger animals (Purves and Lichtman, 1985). These differences in convergence presumably come about because dendritic arbors regulate the number of preganglionic axons that innervate ganglion cells (Hume and Purves, 1981, 1983; Purves, 1983; Purves and Hume, 1981).

Differences in convergence may also have functional implications for autonomic end organs. For example, in the ciliary ganglion of the rabbit, the average frequency of postsynaptic potentials in individual ganglion cells recorded in vivo varies directly with the degree of preganglionic convergence onto each neuron (Johnson and Purves, 1983). Since the axons that innervate superior cervical ganglion cells initiate postsynaptic potentials that can be (and frequently are) above threshold for firing a given ganglion cell (see, for example, $\mathrm{Njå} \mathrm{and} \mathrm{Purves,}$ 1977), increasing degrees of convergence may elicit proportionately greater levels of ongoing activity from each neuron.

\section{Conclusions}

Our findings in the superior cervical ganglion of mice, hamsters, rats, guinea pigs, and rabbits suggest some of the ways that neural systems adapt to the requirements of animal size. Although some increase in neuronal numbers occurs in this pathway, there is an obvious discrepancy between body size and the number of sympathetic nerve cells in progressively larger mammals. Thus, the sympathetic system of larger animals must achieve the same peripheral action with relatively little change in neuronal number. One way that the mammalian sympathetic system appears to compensate for the differences in animal size is by modulating convergence and divergence of preganglionic axons. Since convergence and divergence are determined by dendritic and axonal branching, regulation of neuronal ramification appears to be fundamental in adapting the sympathetic nervous system to operate effectively in animals of different size. The fact that homologous ganglion cells in larger animals have larger dendritic (and terminal) arbors raises the possibility that ganglion cell geometry is regulated by the mass of peripheral targets.

Note added in proof. Two other interesting papers by S. O. E. Ebbesson that bear on the issue we discuss herc have recently been called to our attention (J. Morph. 124: 117-132, 181-186).

\section{References}

Abercrombie, M. (1946) Estimation of nuclear population from microtome sections. Anat. Rec 94: 239-247.

Aguayo, A. J., L. C. Terry, and G. M. Bray (1973) Spontaneous loss of axons in sympathetic unmyelinated nerve fibers of the rat during development. Brain Res. 54: 360-364.

Bok, S. T. (1959) Histonomy of the Cerebral Cortex, Elsevier, Amsterdam.

Brooks-Fournier, R., and R. E. Coggeshall (1981) The ratio of preganglionic axons to postganglionic cells in the sympathetic nervous system of the rat. J. Comp. Neurol. 197: 207-216.

Calder, W. A. (1984) Size, Function and Life History, Harvard, Cambridge, MA.

Cobb, S. (1965) Brain size. Arch. Neurol. 12: 555-561.

Dalsgäard, C.-J., and L. G. Elfvin (1979) Spinal origin of preganglionic fibers projecting onto the superior cervical ganglion and inferior mesenteric ganglion of the guinea-pig, as demonstrated by the horseradish peroxidase technique. Brain Res. 172: 139-143.

Dibner, M. D., and I. B. Black (1978) Biochemical and morphological effects of testosterone treatment on developing sympathetic ncurons. J. Neurochem. 30: 1479-1483. 
Forehand, C. J. (in press) Density of somatic innervation of mammalian ganglion cells is inversely related to dendritic complexity and preganglionic convergence. J. Neurosci.

Frank, E., W. A. Harris, and M. B. Kennedy (1981) Lysophosphotidyl choline facilitates labeling of CNS projections with horseradish peroxidase. J. Neurosci. Meth. 2: 183-189.

Gorin, P. D., and E. M. Johnson, Jr. (1980) Effects of long-term nerve growth factor deprivation on the nervous system of the adult rat: An experimental autoimmune approach. Brain Res. 198: 27-42.

Hendry, I. A., and J. Campbell (1976) Morphometric analysis of rat superior cervical ganglion after axotomy and nerve growth factor treatment. J. Neurocytol. 5: 351-360.

Holloway, R. L., Jr. (1968) The evolution of the primate brain: Some aspects of quantitative relations. Brain Res. 7: 121-172.

Hume, R. I., and D. Purves (1981) Geometry of neonatal neurones and the regulation of synapse elimination. Nature 293: 469-471.

Hume, R. I., and D. Purves (1983) Apportionment of the terminals from single preganglionic axons to target neurones in the rabbit ciliary ganglion. J. Physiol. (Lond.) 338: 259-275.

Johnson, D. A., and D. Purves (1983) Tonic and reflex synaptic activity recorded in ciliary ganglion cells of anaesthetized rabbits. J. Physiol. (Lond.) 339: 599-613.

Johnson, Jr., E. M., P. D. Gorin, L. D. Brandeis, and J. Pearson (1980) Dorsal root ganglion neurons are destroyed by exposure in utero to maternal antibody to nerve growth factor. Science 210: 916-918.

Johnson, Jr., E. M., P. D. Gorin, P. A. Osborne, R. E. Rydell, and J. Pearson (1982) Effects of autoimmune NGF deprivation in the adult rabbit and offspring. Brain Res. 240: 131-140.

Murata, Y., H. Shibata, and T. Chiba (1982) A correlative quantitative study comparing the nerve fibers in the cervical sympathetic trunk and the locus of the somata from which they originate in the rat. J. Autonom. Nerv. Syst. 6: 323-333.

Nieuwenhuys, R. (1967) Comparative anatomy of the cerebellum. Prog. Brain Research 25: 1-93.

Njå, A., and D. Purves (1977) Specific innervation of guinea-pig su- perior cervical ganglion cells by preganglionic fibres arising from different levels of the spinal cord. J. Physiol. (Lond.) 264: 565-583.

Purves, D. (1976) Competitive and non-competitive re-innervation of mammalian sympathetic neurones by native and foreign fibres. $J$. Physiol. (Lond.) 261: 453-475.

Purves, D. (1983) Modulation of neuronal compctition by postsynaptic geometry in autonomic ganglia. Trends Neurosci. 6: 10-16.

Purves, D., and R. I. Hume (1981) The relation of postsynaptic geometry to the number of presynaptic neurones that innervate autonomic ganglion cells. J. Neurosci. 1: 441-452.

Purves, D., and J. W. Lichtman (1985) Geometrical differences among homologous neurons in mammals. Science 228: 298-302.

Purves, D., and D. J. Wigston (1983) Neural units in the superior cervical ganglion of the guinea-pig. J. Physiol. (Lond.) 334: 169-178.

Rando, T. A., C. W. Bowers, and R. E. Zigmond (1981) Localization of neurons in the spinal cord which project to the superior cervical ganglion. J. Comp. Neurol. 196: 73-83.

Rubin, E., and D. Purves (1980) Segmental organization of sympathetic preganglionic neurons in the mammalian spinal cord. J. Comp. Neurol. 192: 163-174.

Schmidt-Nielsen, K. (1984) Scaling: Why is Animal Size So Important? Cambridge U.P., Cambridge.

Thompson, D. W. (1917) On Growth and Form. Cambridge U.P., Cambridge.

Wesselmann, U., and E. M. McLachlan (1984) The effect of previous transection on quantitative estimates of the preganglionic neurones projecting in the cervical sympathetic trunk of the guinea-pig and the cat made by retrograde labelling of damaged axons by horseradish peroxidase. Neuroscience 13: 1299-1309.

Wright, L. L., and A. J. Smolen (1983) Neonatal testosterone treatment increases neuron and synapse numbers in male rat superior cervical ganglion. Dev. Brain Res. 8: 145-153.

Wright, L. L., T. J. Cunningham, and A. J. Smolen (1983) Developmental neuron death in the rat superior cervical ganglion: Cell counts and ultrastructure. J. Neurocytol. 12: 726-783. 